Check for updates

Cite this: RSC Adv., 2017, 7, 20685

Received 25th February 2017

Accepted 4th April 2017

DOI: $10.1039 / c 7 r a 02353 g$

rsc.li/rsc-advances

\title{
Extended visible photosensitivity of carboxyethyltin functionalized polyoxometalates with common organic dyes enabling enhanced photoelectric performance $\uparrow$
}

\author{
Li-Ying Guo, Ying Li, Yao Zhang, Jian-Sheng Li, Wan-Sheng You, Fang Su, \\ Zai-Ming Zhu, ${ }^{*}$ Xiao-Jing Sang* and Lan-Cui Zhang (D) *
}

\begin{abstract}
A kind of broad spectral responsive photoelectrode has been assembled from open-chain carboxyethyltin functionalized Dawson sandwich-type polyoxometalates (POMs) $\left[\left\{\mathrm{Sn}\left(\mathrm{CH}_{2}\right)_{2} \mathrm{COO}_{2} \mathrm{M}_{2}\left(\mathrm{P}_{2} \mathrm{~W}_{15} \mathrm{O}_{56}\right)_{2}\right]^{16-}(\mathrm{SnR}\right.$ $M-P_{2} W_{15}, M=M n, C o, C u$ and $Z n$ ) and organic dyes such as rhodamine $B(R h B)$ and methylene blue (MB) through the layer-by-layer (LBL) self-assembly method. SnR-M-P $\mathrm{W}_{15}$ shows strong adsorption towards $\mathrm{RhB}$ and MB. The adsorption capacity of SnR-Co- $\mathrm{P}_{2} \mathrm{~W}_{15}$ towards RhB and MB reached 217.36 and $288.76 \mathrm{mg} \mathrm{g}^{-1}$ in $10 \mathrm{~min}$, respectively. Compared to Keggin sandwich-type open-chain carboxyethyltin$\mathrm{POM}$ and closed-ring carboxyethyltin-POM derivatives such as $\left[\mathrm{Zn}_{2}\left\{\mathrm{Sn}\left(\mathrm{CH}_{2}\right)_{2} \mathrm{COO}\right\}_{2}\left[\left(\mathrm{PW}_{9} \mathrm{O}_{34}\right)_{2}\right]^{10-}(\mathrm{SnR}-\right.$ $\mathrm{Zn}-\mathrm{PW})$ and $\left[\mathrm{K}_{3}\left\{\mathrm{Sn}\left(\mathrm{CH}_{2}\right)_{2} \mathrm{COO}_{2}\left(\mathrm{PW}_{9} \mathrm{O}_{34}\right)_{2}\right]^{11-}(\mathrm{SnR}-\mathrm{PW})_{9}\right.$, and the parent POMs $\left[\mathrm{M}_{4}\left(\mathrm{H}_{2} \mathrm{O}_{2}\left(\mathrm{P}_{2} \mathrm{~W}_{15} \mathrm{O}_{56}\right)_{2}\right]^{16-}\right.$ $\left(M-P_{2} W_{15}, M=M n, C o, C u\right.$ and $\left.Z n\right), S n R-M-P_{2} W_{15}$-based photoelectrodes showed significantly enhanced photocurrent owing to their greater visible light harvesting. Also, the photoelectric performances of LBL multilayer films can be adjusted by controlling the number of deposited layers, adsorbed dye types and incorporated transition metal ions in the POMs.
\end{abstract}

\section{Introduction}

The development of high-efficiency solar cells represents a promising and desirable approach for the sustainable utilization of clean energy. ${ }^{1-7}$ Typically, for achieving high photovoltaic performances, the photoelectrodes must perform efficient light harvesting with absorption bands in the visible or near-IR region, preferably covering a broad range of wavelengths, and have sufficient electrochemical driving force for solar conversion reactions, slow carrier recombination, stability in the electrolyte, and low cost..$^{8-10}$ Recently, polyoxometalates (POMs), which represent a diverse class of low cost metal-oxide clusters with tunable redox properties and high stability, have been found to be versatile inorganic building blocks for constructing photoelectrochemical and dye-sensitized solar cells. ${ }^{11-20}$ Nevertheless, traditional POMs absorb mainly UV light, which limits their utilization of solar energy. ${ }^{21,22}$ Thus, further boosting their photoelectrochemical performances in

School of Chemistry and Chemical Engineering, Liaoning Normal University, Dalian 116029, China.E-mail: chemzhu@sina.com; sangxj923@nenu.edu.cn; zhanglcui@ $126 . \mathrm{com}$

$\dagger$ Electronic supplementary information (ESI) available: ORTEP views of SnR-Cu- $\mathrm{P}_{2} \mathrm{~W}_{15}$ and SnR-Zn- $\mathrm{P}_{2} \mathrm{~W}_{15}$; IR, NMR, XRPD, TG-DTA, absorption spectra, cyclic voltammograms, adsorption capacity experiment and photoelectric performances. CCDC 1522095 and 1522096. For ESI and crystallographic data in CIF or other electronic format see DOI: 10.1039/c7ra02353g the visible light region still remains a challenge for POM-based photovoltaic systems.

Carboxyethyltin functionalized POMs are a typical series of POM-based derivatives, which have attracted considerable interest recently due to their photoelectrochemical applications. Especially for double-armed type POMs that were cofunctionalized by open-chain carboxyethyltin and transitional metals, in which the transitional metal can bring extra redox centers and enhance visible light photo-response, while the exposed -COO group plays a key role for building POMbased composite systems by further functionalization. ${ }^{23-26}$ Our group has synthesized a series of carboxyethyltin-POM derivatives and further studied their photoelectric and electro-catalytic performances by loading them on semiconductors $^{\mathbf{2 4 , 2 5}}$ and carbon nanotubes. ${ }^{26}$ But it should be noted that their utilization of solar energy is still limited and further functionalization for enhanced visible activity is needed. Liu and Zhang et al. reported the visible-light-driven POM-based photoelectrochemical cells by organic dye-functionalization. ${ }^{15}$ As is known, rhodamine B (RhB) and methylene blue (MB) are of two dye contaminants in wastewater, which show intense absorbance in the visible region. ${ }^{27,28}$ Hence, the composition of carboxyethyltin-POM derivatives with these dyes are expected to form new types of photoelectric materials, and also to be potential for decolorizing treatment of dye wastewater. 
In this work, open-chain carboxyethyltin functionalized Dawson sandwich-type tungstophosphates (SnR-M- $\mathrm{P}_{2} \mathrm{~W}_{15}, \mathbf{M}=$ $\mathrm{Mn}, \mathrm{Co}, \mathrm{Cu}$ and $\mathrm{Zn}$ ) were discovered to show strong adsorption capacity towards $\mathrm{RhB}$ or $\mathrm{MB}$, which can form a kind of broad spectral responsive composite material SnR-M-P $\mathrm{P}_{2} \mathrm{~W}_{15} /$ dye (dye $=\mathrm{RhB}$ or $\mathrm{MB}$ ). Furthermore, because the layer-by-layer (LBL) assembly is a simple and effective way to prepare films with controllable thicknesses, architectures and functionalities on the molecular level, ${ }^{29-32}$ the LBL growth of SnR-M- $\mathrm{P}_{2} \mathrm{~W}_{15}$ and $\mathrm{RhB}$ or MB composite photoelectrodes have been carried out successfully. The self-assembly procedure of the films was illustrated in Scheme 1. Upon visible light irradiation $(\lambda>420$ $\mathrm{nm})$, the photoelectrode (SnR-M-P $\left.\mathrm{W}_{15} / \mathrm{RhB}\right)_{n}$ or $\left(\mathrm{SnR}-\mathrm{M}-\mathrm{P}_{2} \mathrm{~W}_{15} /\right.$ $\mathrm{MB})_{n}(n=1-6)$ shows obvious anodic photocurrent owing to both the extended visible light harvesting by organic dyes and semiconductor-like characteristics of SnR-M- $\mathrm{P}_{2} \mathrm{~W}_{15}$. Additionally, a series of study results demonstrate that the photoelectric performances of the LBL films are different depending on the carboxyethyltin structure, POM structure and incorporated transitional metal types. This work provides valuable insights for POM-based photovoltaic systems on further utilization of solar energy and environment protection.

\section{Experimental}

\section{Chemicals and reagents}

$\mathrm{Na}_{12}\left[\alpha-\mathrm{P}_{2} \mathrm{~W}_{15} \mathrm{O}_{56}\right] \cdot 24 \mathrm{H}_{2} \mathrm{O}\left(\mathrm{P}_{2} \mathrm{~W}_{15}\right)$ and $\mathrm{Na}_{16}\left[\mathrm{M}_{4}\left(\mathrm{H}_{2} \mathrm{O}\right)_{2}\left(\mathrm{P}_{2} \mathrm{~W}_{15^{-}}\right.\right.$ $\left.\left.\mathrm{O}_{56}\right)_{2}\right] \cdot n \mathrm{H}_{2} \mathrm{O}\left(\mathrm{M}-\mathrm{P}_{2} \mathrm{~W}_{15}\right)$ were prepared according to the reported procedures. ${ }^{33-36} \mathrm{Cl}_{3} \mathrm{SnCH}_{2} \mathrm{CH}_{2} \mathrm{COOCH}_{3}$ (SnR) and $\mathrm{Cl}_{3} \mathrm{SnCH}_{2}$ $\mathrm{CH}_{2} \mathrm{COOH}$ (SnR-COOH) were synthesized by the literature methods. ${ }^{37} \quad\left\{\mathrm{C}\left(\mathrm{NH}_{2}\right)_{3}\right\}_{12} \mathrm{H}_{4}\left[\left\{\left(\mathrm{Sn}\left(\mathrm{C}_{3} \mathrm{H}_{4} \mathrm{O}_{2}\right)\right)_{2} \mathrm{M}_{2}\left(\mathrm{P}_{2} \mathrm{~W}_{15} \mathrm{O}_{56}\right)_{2}\right\}\right]$. $n \mathrm{H}_{2} \mathrm{O}$ (SnR-M-P $\mathrm{P}_{2} \mathrm{~W}_{15}, \mathrm{M}=\mathrm{Mn}, n=22 ; \mathrm{M}=\mathrm{Co}, n=14$ ) have been previously prepared in our group. ${ }^{25,38}$ Herein, we added transitional metal ion $\mathrm{Cu}^{2+}$ and $\mathrm{Zn}^{2+}$ into the array of POMs, and complete details of this case will be provided at a later time. Together, these four representative POMs with the general abbreviative formula of SnR-M-P $\mathrm{W}_{15}(\mathrm{M}=\mathrm{Mn}, \mathrm{Co}, \mathrm{Cu}, \mathrm{Zn})$ represent the Dawson sandwich-type open-chain carboxyethyltin functionalized POMs. We also prepared the Keggin sandwich-type open-chain carboxyethyltin functionalized POM
$\mathrm{Na}_{8} \mathrm{~K}_{2}\left[\mathrm{Zn}_{2}\left\{\mathrm{Sn}\left(\mathrm{CH}_{2}\right)_{2} \mathrm{COO}\right\}_{2}\left[\left(\mathrm{PW}_{9} \mathrm{O}_{34}\right)_{2}\right] \cdot 13 \mathrm{H}_{2} \mathrm{O} \quad\left(\mathrm{SnR}-\mathrm{Zn}-\mathrm{PW}_{9}\right)^{39}\right.$ and Keggin sandwich-type closed-ring carboxyethyltin functionalized $\mathrm{POM} \quad \mathrm{Na}_{3} \mathrm{~K}_{8}\left[\mathrm{~K}_{3}\left\{\mathrm{Sn}\left(\mathrm{CH}_{2}\right)_{2} \mathrm{COO}\right\}_{2}\left(\mathrm{PW}_{9} \mathrm{O}_{34}\right)_{2}\right] \cdot 18 \mathrm{H}_{2} \mathrm{O}$ $\left(\mathrm{SnR}-\mathrm{PW}_{9}\right)^{\mathbf{4 0}}$ for comparative experiments. All of them were characterized by IR spectroscopy. Poly(ethylenimine) (PEI; MW $=750$ 000) and poly(styrenesulfonate) (PSS; MW = 70 000) were purchased from Aldrich and used without further treatment. All other reagents and chemicals were commercially purchased and used without further purification.

\section{Synthesis of $\left\{\mathrm{C}\left(\mathrm{NH}_{2}\right)_{3}\right\}_{12} \mathrm{H}_{4}\left[\left\{\mathrm{Sn}\left(\mathrm{CH}_{2}\right)_{2} \mathrm{COO}\right\}_{2} \mathrm{Cu}_{2}\left(\mathrm{P}_{2} \mathrm{~W}_{15} \mathrm{O}_{56}\right)_{2}\right]$. $14 \mathrm{H}_{2} \mathrm{O}\left(\mathrm{SnR}-\mathrm{Cu}-\mathrm{P}_{2} \mathrm{~W}_{15}\right)$}

SnR-Cu- $\mathrm{P}_{2} \mathrm{~W}_{15}$ was successfully synthesized by referring to our previous method ${ }^{25,38}$ and making small variations. SnR (0.12 g, $0.38 \mathrm{mmol}$ ) was dissolved in $30 \mathrm{~mL}$ of $0.5 \mathrm{~mol} \mathrm{~L}^{-1} \mathrm{NaCl}$ aqueous solution under vigorous stirring. Then, Cu- $\mathrm{P}_{2} \mathrm{~W}_{15}(0.20 \mathrm{~g}, 0.02$ $\mathrm{mmol}$ ) was added in small portions to obtain a clear, light-green solution. The resulting mixture was further stirred for $3 \mathrm{~h}$ at $80-$ $90{ }^{\circ} \mathrm{C}$. After cooling to room temperature, a small amount of insoluble precipitate was filtered off, and the filtrate was dealt with $\mathrm{KCl}(0.25 \mathrm{~g})$ and $\mathrm{C}\left(\mathrm{NH}_{2}\right)_{3} \mathrm{Cl}$ aqueous solution $\left(1.0 \mathrm{~mol} \mathrm{~L}^{-1}\right.$, $1.8 \mathrm{~mL}$ ). Slow evaporation of the mixture solution at $40-60{ }^{\circ} \mathrm{C}$ resulted in light-green block-like crystals after about two weeks (yield $31 \%$ based on $\mathrm{W}$ ). Anal. calcd for $\mathrm{C}_{18} \mathrm{H}_{112} \mathrm{O}_{130} \mathrm{~N}_{36} \mathrm{Cu}_{2}$ $\mathrm{Sn}_{2} \mathrm{P}_{4} \mathrm{~W}_{30}$ (\%): C 2.42, H 1.27, N 5.65, P 1.39, Cu 1.43, Sn 2.66, W 61.85. Found (\%): C 2.45, H 1.31, N 5.69, P 1.46, Cu 1.48, Sn 2.70, W 61.91. FTIR (solid $\mathrm{KBr}$ pellet $\nu / \mathrm{cm}^{-1}$ ): 3434(s), 3266(w), 3185(w), 2918(w), 2855(w), 1668(s), 1395(w), 1097(s), 954(m), $903(\mathrm{w}), 761(\mathrm{~m}), 624(\mathrm{w}), 524(\mathrm{w}), 425(\mathrm{w})$.

\section{Synthesis of $\left\{\mathrm{C}\left(\mathrm{NH}_{2}\right)_{3}\right\}_{11} \mathrm{H}_{5}\left[\left\{\mathrm{Sn}\left(\mathrm{CH}_{2}\right)_{2} \mathrm{COO}\right\}_{2} \mathrm{Zn}_{2}\left(\mathrm{P}_{2} \mathrm{~W}_{15} \mathrm{O}_{56}\right)_{2}\right]$. $1_{2} \mathrm{H}_{2} \mathrm{O}\left(\mathrm{SnR}-\mathrm{Zn}-\mathrm{P}_{2} \mathrm{~W}_{15}\right)$}

Detailed synthesis of SnR-Zn- $\mathrm{P}_{2} \mathrm{~W}_{15}$ is similar to that of SnR-Cu$\mathrm{P}_{2} \mathrm{~W}_{15}$, except using $\mathrm{Zn}-\mathrm{P}_{2} \mathrm{~W}_{15}(0.20 \mathrm{~g}, 0.02 \mathrm{mmol})$ to replace $\mathrm{Cu}$ $\mathrm{P}_{2} \mathrm{~W}_{15}$, and colorless block-like crystalline SnR-Zn- $\mathrm{P}_{2} \mathrm{~W}_{15}$ was isolated after two weeks (yield $34 \%$ based on W). Anal. calcd for $\mathrm{C}_{17} \mathrm{H}_{105} \mathrm{O}_{129} \mathrm{~N}_{33} \mathrm{Zn}_{2} \mathrm{Sn}_{2} \mathrm{P}_{4} \mathrm{~W}_{30}$ (\%): C 2.31, H 1.20, N 5.23, P 1.40, Zn 1.48, Sn 2.68, W 62.36. Found (\%): C 2.38, H 1.24, N 5.27, P 1.46, Zn 1.52, Sn 2.72, W 62.44. FTIR (solid KBr pellet $\nu / \mathrm{cm}^{-1}$ ):

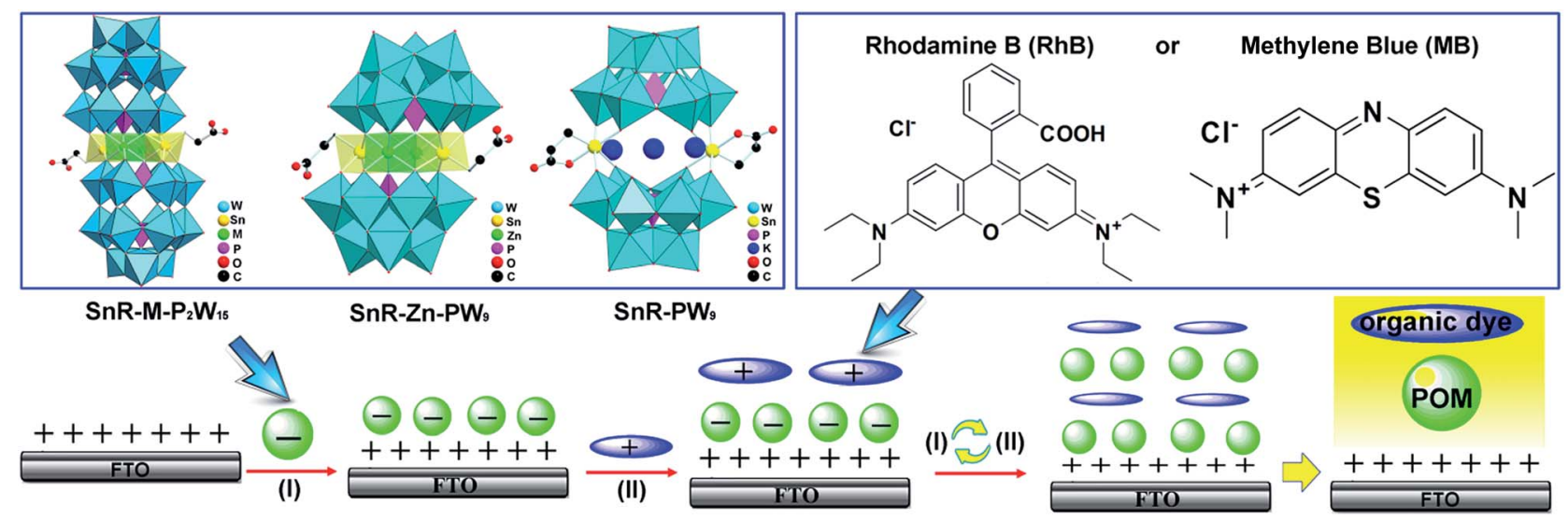

Scheme 1 Schematic depiction of the buildup of the LBL multilayer films, and the structural representations of POMs and RhB and MB. 
3436(s), 3259(w), 3187(w), 2916(w), 2853(w), 1666(s), 1400(w), 1096(s), 952(m), 912(w), 760(m), 624(w), 526(w), 421(w).

\section{Dye adsorption experiments}

SnR-M- $\mathrm{P}_{2} \mathrm{~W}_{15}(\mathrm{M}=\mathrm{Mn}, \mathrm{Co}, \mathrm{Cu}$ and $\mathrm{Zn})$ (34 mg) was dissolved in water $(5 \mathrm{~mL})$, followed by adding tetrabutylammonium bromide (TBA) to balance the charges in POMs. The $\mathrm{pH}$ of solution was adjusted to 4.0 by using a certain amount of $\mathrm{NaOH}$ or $\mathrm{HCl}$ solution, to which $\mathrm{RhB}\left(2.0 \mathrm{~g} \mathrm{~L}^{-1}, 5 \mathrm{~mL}\right)$ solution was mixed together and stirred vigorously. Instantly, vast pink precipitate emerges, which was centrifugally separated for further analysis. The adsorption of SnR-M- $\mathrm{P}_{2} \mathrm{~W}_{15}$ towards $\mathrm{MB}$ is similar to that of SnR-M- $\mathrm{P}_{2} \mathrm{~W}_{15}$ towards RhB, except using $\mathrm{MB}$ solution $\left(2.0 \mathrm{~g} \mathrm{~L}^{-1}\right)$ to replace $\mathrm{RhB}$ solution, and cyaneous precipitate momently appeared, which was centrifugally separated for further analysis.

\section{LBL growth of $\left(\text { SnR-M-P } \mathrm{W}_{15} / \text { dye }\right)_{n}$ films $($ dye $=$ RhB or MB $)$}

Various substrates including quartz plate, silicon wafers, $\mathrm{CaF}_{2}$ and FTO glasses were ultrasonically cleaned with detergent solution, deionized water, acetone and ethanol successively. Then these substrates were processed with piranha solution for 30 min (ref. 41) except for $\mathrm{CaF}_{2}$. After being rinsed with deionized water and dried under a stream of nitrogen, the cleaned substrate was immersed in PEI solution $\left(1.0 \mathrm{mg} \mathrm{mL}^{-1}\right)$ for $30 \mathrm{~min}$, followed by rinsing with deionized water and drying under nitrogen atmosphere. The PEI-coated substrates were then alternately immersed into SnR-M-P $\mathrm{W}_{15}$ solution $(10 \mathrm{~mL}$, $\left.3.69 \mathrm{mmol} \mathrm{L}^{-1}\right)$ for $30 \mathrm{~min}$ and RhB solution $(10 \mathrm{~mL}, 4.18 \mathrm{mmol}$ $\mathrm{L}^{-1}$ ) for $30 \mathrm{~min}$, and also rinsed with deionized water and dried under nitrogen after each dipping step. Subsequently, this process was repeated for certain times to obtain (SnR-M- $\mathrm{P}_{2} \mathrm{~W}_{15}$ ) $\mathrm{RhB})_{n}$ films. Besides, $\left(\mathrm{SnR}-\mathrm{M}-\mathrm{P}_{2} \mathrm{~W}_{15} / \mathrm{MB}\right)_{n}$ films were fabricated with the same way except using MB instead of RhB.

\section{LBL growth of other composite films}

The assembly of other composite films were similar to that of (SnR-M-P $\left.\mathrm{W}_{15} / \mathrm{RhB}\right)_{n}$ films, except using SnR-Zn-PW 9 , SnR-PW $\mathrm{M}-\mathrm{P}_{2} \mathrm{~W}_{15}, \mathrm{P}_{2} \mathrm{~W}_{15}$ and PSS instead of SnR-M-P $\mathrm{W}_{15}$, and moreover using PEI instead of RhB. They were marked as (SnR-Zn$\left.\mathrm{PW}_{9} / \mathrm{RhB}\right)_{n}, \quad\left(\mathrm{SnR}_{-} \mathrm{PW} / \mathrm{RhB}\right)_{n}, \quad\left(\mathrm{M}-\mathrm{P}_{2} \mathrm{~W}_{15} / \mathrm{RhB}\right)_{n},\left(\mathrm{P}_{2} \mathrm{~W}_{15} / \mathrm{RhB}\right)_{n}$, $(\mathrm{PSS} / \mathrm{RhB})_{n}$ and (PEI/SnR-M-P $\left.\mathrm{W}_{15}\right)_{n}$, respectively.

\section{Characterization methods}

Single crystal X-ray diffraction data were collected on a Bruker Smart APEX II X-diffractometer equipped with graphitemonochromated Mo $\mathrm{K} \alpha$ radiation $(\lambda=0.71073 \AA)$. C, $\mathrm{H}$ and $\mathrm{N}$ elemental analyses were performed on a VarioElcube elemental analyzer, and P, Sn, Cu, Zn and W were analyzed on a Prodigy XP emission spectrometer. IR spectra were recorded using $\mathrm{KBr}$ pellets on a Bruker AXS TENSOR-27 FTIR spectrometer in the range of $4000-400 \mathrm{~cm}^{-1}$. UV/Vis absorption spectra were recorded on a Lambda $35 \mathrm{UV} / \mathrm{Vis}$ spectrophotometer. TG analyses were performed on a Pyris Diamond TG-DTA thermal analyzer at the heating rate of $10^{\circ} \mathrm{C} \mathrm{min}^{-1}$ in air atmosphere. $\mathrm{X}$ - ray powder diffraction data were collected on a Bruker AXS D8 Advance diffractometer using $\mathrm{Cu} \mathrm{K}_{\alpha}$ radiation $(\lambda=1.5418 \AA)$ in the $2 \theta$ range of $5-50^{\circ}$ with a step size of $0.02^{\circ}$. NMR spectra were recorded at room temperature on a Bruker AVANCE 500 spectrometer with an inner tube containing $\mathrm{D}_{2} \mathrm{O}$ for instrumental lock. Phosphorus and tin chemical shifts were referenced to $85 \% \quad \mathrm{H}_{3} \mathrm{PO}_{4}$ and $\left(\mathrm{CH}_{3}\right)_{4} \mathrm{Sn}$, respectively. The solid diffuse reflectivity spectra were collected on a Cary series UV/Vis spectrophotometer in reflectance mode, which was measured from 200 to $800 \mathrm{~nm}$ using $\mathrm{BaSO}_{4}$ as a standard with $100 \%$ reflectance. The photoluminescence properties were determined on a RILI F-7000 fluorescence spectrophotometer in the solid state at room temperature. The X-ray photoelectron spectroscopy (XPS) spectra were recorded on a Thermo Electron ESCALAB-250 spectrometer with a monochromic X-ray source $\left(\mathrm{Al} \mathrm{K}_{\alpha}\right.$ line, $1486.6 \mathrm{eV}$ ). Atomic force microscopy (AFM) analysis were carried out using a Veeco Multimode Nanoscope IVA in tapping mode using silicon cantilevers (Bruker, RTESP) with radius of curvature less than $10 \mathrm{~nm}$. The photoelectrochemical experiments were performed on a CHI604B electrochemical workstation. A three-electrode system was employed in a quartz cell with an Ag/ $\mathrm{AgCl}$ electrode as the reference electrode, a platinum wire as the counter electrode and the hybrid films assembled on FTO electrode with an effective area of $1.0 \times 1.0 \mathrm{~cm}^{2}$ as the working electrode. A $300 \mathrm{~W}$ Xe lamp using the light filter of 420-780 nm was used as a light source, and the average intensity of irradiance reaching the composite films was measured to be $c a$. $100 \mathrm{~mW} \mathrm{~cm}^{-2}$ with a Model ST-900M photometer. All photoelectrochemical measurements were done in $0.1 \mathrm{~mol} \mathrm{~L}^{-1}$ $\mathrm{Na}_{2} \mathrm{SO}_{4}$ electrolyte which was exposed to air.

\section{X-ray crystallography}

The structures were solved by direct methods and refined on $F^{2}$ by full-matrix least-squares fitting using SHELXTL-2014. Crystal data and structure refinement parameters of SnR-Cu- $\mathrm{P}_{2} \mathrm{~W}_{15}$ and SnR-Zn- $\mathrm{P}_{2} \mathrm{~W}_{15}$ are listed in Table 1 . Hydrogen atoms were added on $\mathrm{C} / \mathrm{N}$ atoms in calculated positions. In $\mathrm{SnR}-\mathrm{Cu}-\mathrm{P}_{2} \mathrm{~W}_{15}$ and SnR-Zn- $\mathrm{P}_{2} \mathrm{~W}_{15}$, only some of lattice water molecules were accurately assigned from the residual electron peaks, whereas the rest were directly included in the molecular formula on the basis of the SQUEEZE calculation results, the elemental analysis and TG analysis. Selected bond lengths and angles are listed in Tables S1 and S2.† Hydrogen bonds are listed in Tables $\mathrm{S} 3$ and $\mathrm{S} 4 . \dagger$

\section{Results and discussion}

\section{Crystal structure analysis}

Single-crystal X-ray diffraction analysis reveals that SnR-Cu$\mathrm{P}_{2} \mathrm{~W}_{15}$ and SnR-Zn- $\mathrm{P}_{2} \mathrm{~W}_{15}$ display the well-known Dawson sandwich-type structures, and the structures are isostructural with those of our previously reported compounds. ${ }^{25,33}$ Two symmetrical units consisting of $\left[\mathrm{P}_{2} \mathrm{~W}_{15} \mathrm{O}_{56}\right]^{12-}$ were subunited by two $\mathrm{Cu}^{2+}$ or $\mathrm{Zn}^{2+}$ ions and two carboxyethyltin groups (Fig. S1 $\dagger$ ). In SnR-Cu- $\mathrm{P}_{2} \mathrm{~W}_{15}$ and SnR-Zn- $\mathrm{P}_{2} \mathrm{~W}_{15}$, each $\left[\mathrm{P}_{2} \mathrm{~W}_{15} \mathrm{O}_{56}\right]^{12-}$ unit supplies seven oxygen atoms (one central 
Table 1 Crystal and refinement data for SnR-Cu- $\mathrm{P}_{2} \mathrm{~W}_{15}$ and SnR-Zn$\mathrm{P}_{2} \mathrm{~W}_{15}$

\begin{tabular}{|c|c|c|}
\hline Compound & SnR-Cu- $\mathrm{P}_{2} \mathrm{~W}_{15}$ & SnR-Zn- $\mathrm{P}_{2} \mathrm{~W}_{15}$ \\
\hline Formula & $\begin{array}{l}\mathrm{C}_{18} \mathrm{H}_{112} \mathrm{O}_{130} \mathrm{~N}_{36^{-}} \\
\mathrm{Cu}_{2} \mathrm{Sn}_{2} \mathrm{P}_{4} \mathrm{~W}_{30}\end{array}$ & $\begin{array}{l}\mathrm{C}_{17} \mathrm{H}_{105} \mathrm{O}_{129} \mathrm{~N}_{33^{-}} \\
\mathrm{Zn}_{2} \mathrm{Sn}_{2} \mathrm{P}_{4} \mathrm{~W}_{30}\end{array}$ \\
\hline Formula weight & 8917.27 & 8843.83 \\
\hline$T / \mathrm{K}$ & $296(2)$ & $296(2)$ \\
\hline Wavelength/Å & 0.71073 & 0.71073 \\
\hline Crystal system & Monoclinic & Monoclinic \\
\hline Space group & $P 2(1) / n$ & $P 2(1) / n$ \\
\hline$a / \AA$ & $13.3227(7)$ & $13.3099(7)$ \\
\hline$b / \AA$ & $32.2012(16)$ & $32.1189(18)$ \\
\hline$c / \AA$ & $19.0960(10)$ & $18.9918(10)$ \\
\hline$\beta /^{\circ}$ & $94.0540(10)$ & $94.0490(10)$ \\
\hline$V / \AA^{3}, Z$ & $8171.8(7), 2$ & 8098.7(8), 2 \\
\hline$D_{\mathrm{c}} / \mathrm{g} \mathrm{cm}^{-3}, F_{000}$ & $3.624,7900$ & $3.627,7820$ \\
\hline GOF & 1.015 & 1.038 \\
\hline Reflections & 42009 & 40460 \\
\hline$R_{\text {int }}$ & 0.0771 & 0.0606 \\
\hline$\theta$ range $\left(^{\circ}\right)$ & $1.805-25.00$ & $1.660-25.00$ \\
\hline$R_{1}(I>2 \sigma(I))^{a}$ & 0.0501 & 0.0455 \\
\hline $\mathrm{w}_{2}{\text { (all data })^{a}}$ & 0.1264 & 0.1109 \\
\hline
\end{tabular}

and six terminal oxygen atoms) that are able to coordinate with two edge-sharing $\mathrm{CuO}_{6}$ or $\mathrm{ZnO}_{6}$ octahedra as well as two openchain $\left[\mathrm{Sn}\left(\mathrm{CH}_{2}\right)_{2} \mathrm{COO}\right]^{2+}$ moieties. Sn1 is hexa-coordinated with five oxygen atoms (O3/O5, O27/O26, O35/O29, O39/43 and O52/ O55) and one carbon atom (C1) derived from a carboxyethyl group (Fig. S2(a) and (b) †). The $\mathrm{Sn}-\mathrm{O}$ bond distances are 2.056(13)-2.290(14) and 2.045(11)-2.300(11) $\AA$, and the Sn-C bond distances are 2.12(3) and 2.12(2) $\AA$ for SnR-Cu- $\mathrm{P}_{2} \mathrm{~W}_{15}$ and SnR-Zn- $\mathrm{P}_{2} \mathrm{~W}_{15}$, respectively. The bond lengths of $\mathrm{Cu}-\mathrm{O}$ and $\mathrm{Zn}-$ $\mathrm{O}$ are in the range of 2.005(15)-2.241(15) and 2.028(11)2.250(12) $\AA$. The bond lengths of $\mathrm{W}-\mathrm{O}$ are in the range of 1.683(13)-2.396(13) and 1.680(12)-2.411(11) A (Tables S1 and $\mathrm{S} 2 \dagger)$ for SnR-Cu- $\mathrm{P}_{2} \mathrm{~W}_{15}$ and SnR-Zn- $\mathrm{P}_{2} \mathrm{~W}_{15}$, respectively. Moreover, the guanidinium $\left[\mathrm{C}\left(\mathrm{NH}_{2}\right)_{3}\right]^{+}$cations and lattice water molecules locate around the polyoxoanions. Furthermore, in SnR-Zn- $\mathrm{P}_{2} \mathrm{~W}_{15}$, two $\left[\mathrm{C}\left(\mathrm{NH}_{2}\right)_{3}\right]^{+}$cations locate with $50 \%$ occupancy. For the packing arrangements of SnR-Cu- $\mathrm{P}_{2} \mathrm{~W}_{15}$ and SnR$\mathrm{Zn}-\mathrm{P}_{2} \mathrm{~W}_{15}$ (Fig. $\mathrm{S} 3 \uparrow$ ), the sandwich-type polyoxoanions accumulated to form 3D supramolecular frameworks by hydrogen bonds (Tables $\mathrm{S} 3$ and $\mathrm{S} 4, \uparrow \mathrm{N}-\mathrm{H} \cdots \mathrm{O} / \mathrm{OW} 1.91-2.64$ and 1.93-2.63 $\AA$ for SnR-Cu- $\mathrm{P}_{2} \mathrm{~W}_{15}$ and SnR-Zn- $\mathrm{P}_{2} \mathrm{~W}_{15}$, respectively) between $\left[\mathrm{C}\left(\mathrm{NH}_{2}\right)_{3}\right]^{+}$cations and polyoxoanions or water molecules, along with the electrostatic forces existing in $\left[\mathrm{C}\left(\mathrm{NH}_{2}\right)_{3}\right]^{+}$cations and polyoxoanions. CCDC-1522095 and CCDC-1522096 contain the supplementary crystallographic data for this paper.

IR spectra (Fig. S4 $\dagger$ ) further confirmed the structures of SnR$\mathrm{Cu}-\mathrm{P}_{2} \mathrm{~W}_{15}$ and SnR-Zn- $\mathrm{P}_{2} \mathrm{~W}_{15}$. The ${ }^{119} \mathrm{Sn}$ and ${ }^{31} \mathrm{P}$ NMR spectra (Fig. S5-S7 $\dagger$ ) proved the stability of SnR-Cu- $\mathrm{P}_{2} \mathrm{~W}_{15}$ and SnR-Zn$\mathrm{P}_{2} \mathrm{~W}_{15}$ in aqueous solution. UV/Vis spectra of SnR-Cu- $\mathrm{P}_{2} \mathrm{~W}_{15}$ and SnR-Zn- $\mathrm{P}_{2} \mathrm{~W}_{15}$ exhibited a strong absorbance band at $273 \mathrm{~nm}$ in the near-UV region (Fig. S8 $\dagger$ ). From the TG analysis (Fig. S9†), the structures of carboxyethyltin-POMs still retain before $490{ }^{\circ} \mathrm{C}$. And the purities of SnR-Cu- $\mathrm{P}_{2} \mathrm{~W}_{15}$ and SnR-Zn- $\mathrm{P}_{2} \mathrm{~W}_{15}$ were confirmed by the consistent peak position of experimental and simulated results in XRPD (Fig. S10†). From the cyclic voltammograms in Fig. S11 and S12, $\dagger$ the electrochemical responses of the $\mathrm{W}$ centers were obviously observed. ${ }^{38}$

\section{Adsorption capability of SnR-M-P $\mathbf{P}_{\mathbf{1 5}}$ towards organic dyes}

To evaluate and compare the adsorption capability of SnR-M$\mathrm{P}_{2} \mathrm{~W}_{15}$ and $\mathrm{M}-\mathrm{P}_{2} \mathrm{~W}_{15}$, the UV/Vis absorption spectra of RhB or MB solution were detected before and after the adsorption process (Fig. S13 and S14†). The adsorption capacity $\left(q_{t}, \mathrm{mg} \mathrm{g}^{-1}\right)$ was calculated according to the following equations: $q_{t}=\left(c_{\mathrm{o}}-\right.$ $\left.c_{t}\right) V / m$, where $c_{\mathrm{o}}$ and $c_{t}\left(\mathrm{mg} \mathrm{L}^{-1}\right)$ represent the initial and final concentration of RhB or MB solution at certain interval time $t$ (min); $V(\mathrm{~mL})$ was the final volume of RhB (MB) after mixing $\mathrm{RhB}(\mathrm{MB})$ and SnR-M-P $\mathrm{P}_{2} \mathrm{~W}_{15}$ solution; $m(\mathrm{mg})$ was the mass of SnR-M-P $\mathrm{P}_{15}$. From Fig. S13, $\dagger$ it is clearly shown that SnR-M$\mathrm{P}_{2} \mathrm{~W}_{15}$ displays a fast adsorption rate towards the cationic dyes RhB and MB. Also, Table 2 lists the $q_{t}$ values of various compounds, from which it is observed that the adsorption capacity of SnR-M- $\mathrm{P}_{2} \mathrm{~W}_{15}$ towards $\mathrm{MB}$ was larger than that of $\mathrm{RhB}$; furthermore, the parent POMs $\left(\mathrm{M}-\mathrm{P}_{2} \mathrm{~W}_{15}\right)$ showed the lower adsorption capacity than their corresponding carboxyethyltin derivatives, and the $q_{t}$ of SnR-Co- $\mathrm{P}_{2} \mathrm{~W}_{15}$ towards MB reached to $288.76 \mathrm{mg} \mathrm{g}^{-1}$ in $10 \mathrm{~min}$. So an interesting finding is that the functionalization of open-chain carboxyethyltin improved the adsorption ability of sandwich-type POMs.

After adsorption, the adsorbent was separated by centrifugation, resulting in the formation of pink precipitate (SnR-M$\mathrm{P}_{2} \mathrm{~W}_{15} / \mathrm{RhB}$ ) or cyaneous precipitate (SnR-M- $\mathrm{P}_{2} \mathrm{~W}_{15} / \mathrm{MB}$ ). SnR-M$\mathrm{P}_{2} \mathrm{~W}_{15} / \mathrm{RhB}$ was further characterized by FTIR (Fig. S15†) and solid UV/Vis absorption spectra (Fig. S16 $\dagger$ ). From the results of FTIR spectra, both SnR-M- $\mathrm{P}_{2} \mathrm{~W}_{15}$ and RhB maintain their stable structures after adsorption. Fig. S16 $†$ reveals that SnR-M-P $\mathrm{P}_{2} \mathrm{~W}_{15} /$ $\mathrm{RhB}$ show two strong broad absorption bands centering at about $286-287$ and $562-564 \mathrm{~nm}$ in the ultraviolet and visible regions, corresponding to the ligand to metal $(\mathrm{O} \rightarrow \mathrm{W})$ charge transfer (LMCT) transition of POMs and $\pi-\pi^{*}$ transition of $\mathrm{RhB}$, respectively. ${ }^{25,42}$ As compared to SnR-M- $\mathrm{P}_{2} \mathrm{~W}_{15}$, the LMCT transition peak for SnR-M- $\mathrm{P}_{2} \mathrm{~W}_{15} / \mathrm{RhB}$ blue shifted, which might be attributed to the decreased size of SnR-M- $\mathrm{P}_{2} \mathrm{~W}_{15}$ after adsorption.

Table 2 Adsorption capacity of various compounds towards RhB and $\mathrm{MB}$

\begin{tabular}{lll}
\hline Compounds & $\begin{array}{l}\text { Adsorption capacity } \\
(\mathrm{RhB})\left(\mathrm{mg} \mathrm{g}^{-1}\right)\end{array}$ & $\begin{array}{l}\text { Adsorption capacity } \\
(\mathrm{MB})\left(\mathrm{mg} \mathrm{g}^{-1}\right)\end{array}$ \\
\hline SnR-Mn- $\mathrm{P}_{2} \mathrm{~W}_{15}$ & 190.98 & 283.22 \\
SnR-Co- $\mathrm{P}_{2} \mathrm{~W}_{15}$ & 217.36 & 288.76 \\
SnR-Cu- ${ }_{2} \mathrm{~W}_{15}$ & 179.02 & 263.47 \\
SnR-Zn- $\mathrm{P}_{2} \mathrm{~W}_{15}$ & 161.15 & 252.46 \\
$\mathrm{Mn}-\mathrm{P}_{2} \mathrm{~W}_{15}$ & 158.07 & 237.28 \\
Co- $\mathrm{P}_{2} \mathrm{~W}_{15}$ & 70.42 & 174.93 \\
$\mathrm{Cu}-\mathrm{P}_{2} \mathrm{~W}_{15}$ & 23.39 & 42.27 \\
Zn- $\mathrm{P}_{2} \mathrm{~W}_{15}$ & 35.29 & 44.54 \\
$\mathrm{P}_{2} \mathrm{~W}_{15}$ & 127.44 & 170.07
\end{tabular}




\section{Characterization of LBL assembly films}

$\mathrm{UV} / \mathrm{Vis}$ spectra were adopted to monitor the deposition process of LBL assembly films. Given that the polyoxoanions SnR-M$\mathrm{P}_{2} \mathrm{~W}_{15}(\mathrm{M}=\mathrm{Mn}, \mathrm{Co}, \mathrm{Cu}, \mathrm{Zn})$ are isostructural, (SnR-Co- $\mathrm{P}_{2} \mathrm{~W}_{15} /$ $\mathrm{RhB})_{n}$ or (SnR-Co- $\left.\mathrm{P}_{2} \mathrm{~W}_{15} / \mathrm{MB}\right)_{n}$ films were taken as an example for describing the structural and morphological characterization of composite films. As shown in Fig. 1(a), the absorbance of $\left(\text { SnR-Co- } \mathrm{P}_{2} \mathrm{~W}_{15} / \mathrm{RhB}\right)_{n} \quad(n=1-6)$ film on quartz substrate increased progressively as the bilayer number, indicating that the composite film was successfully fabricated. In addition, the inset of Fig. 1(a) shows the plot of absorbance at $\lambda=573 \mathrm{~nm}$ versus the bilayer number $n$ results in a nearly straight line, which proved the composite film is well-proportioned and both in the near-UV and visible regions, in which the LMCT absorption band of SnR-Co- $\mathrm{P}_{2} \mathrm{~W}_{15}$ in the UV region is overlapped by the absorption peak of $\mathrm{RhB}$, and the visible peaks are assigned to the $\pi-\pi^{*}$ transition of $\mathrm{RhB}$, respectively. Meanwhile, compared with the absorption peak of RhB solution (554 $\mathrm{nm})$, the absorption peak of RhB in (SnR-Co- $\left.\mathrm{P}_{2} \mathrm{~W}_{15} / \mathrm{RhB}\right)_{n}$ film $(573 \mathrm{~nm})$ red shifted, indicating RhB molecules form J-aggregates. ${ }^{43}$ Similarly, from Fig. 1(b) it was concluded that (SnR-Co$\left.\mathrm{P}_{2} \mathrm{~W}_{15} / \mathrm{MB}\right)_{n}$ film was successfully assembled and the formed composite film is well-proportioned and homogeneous.

The surface morphology and homogeneity of the multilayer films were observed by atomic force microscope (AFM) images (Fig. 2(a) and (b)). As can be seen, the surface of (SnR-Co- $\mathrm{P}_{2} \mathrm{~W}_{15}$ ) $\mathrm{RhB})_{4}$ film $\left(R_{\mathrm{q}}=3.19 \mathrm{~nm}, R_{\mathrm{a}}=2.35 \mathrm{~nm}\right)$ is more rough than that of $(\mathrm{PSS} / \mathrm{RhB})_{4}$ film $\left(R_{\mathrm{q}}=2.68 \mathrm{~nm}, R_{\mathrm{a}}=1.66 \mathrm{~nm}\right)$, which was probably because of the rigid structure and aggregation of POM anions. In addition, the AFM image $\left(\mathrm{Co}-\mathrm{P}_{2} \mathrm{~W}_{15} / \mathrm{RhB}\right)_{4}$ film also shows rough surface and prominent aggregated particles (Fig. S17 $\dagger$ ). Fig. 2(c) portrays the FTIR spectra of (SnR-M- $\mathrm{P}_{2} \mathrm{~W}_{15} /$ $\mathrm{RhB})_{4}$ films $(\mathrm{M}=\mathrm{Mn}, \mathrm{Co}, \mathrm{Cu}$ and $\mathrm{Zn})$ and $(\mathrm{PSS} / \mathrm{RhB})_{4}$ film on $\mathrm{CaF}_{2}$ substrate. In comparison with (PSS/RhB) ${ }_{4}$ film, (SnR-M$\left.\mathrm{P}_{2} \mathrm{~W}_{15} / \mathrm{RhB}\right)_{4}$ films exhibit the characteristic bands of SnR-M-
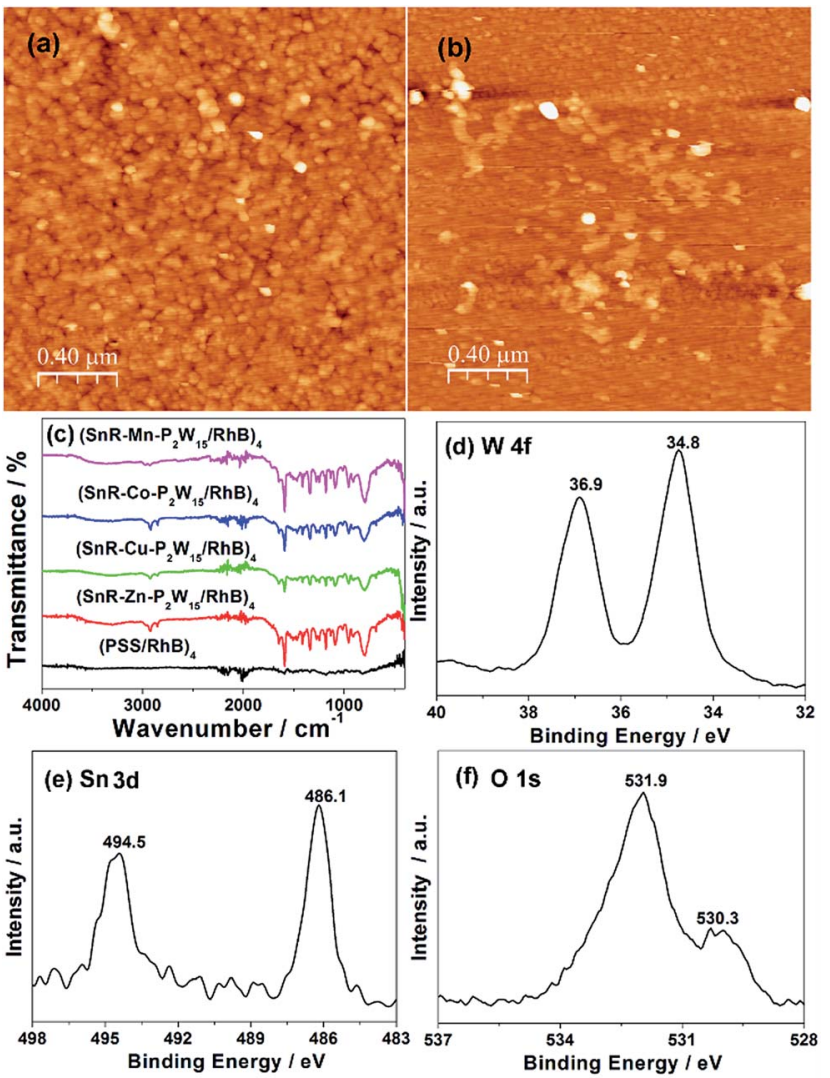

Fig. 2 The AFM images of $\left(\mathrm{SnR}-\mathrm{Co}-\mathrm{P}_{2} \mathrm{~W}_{15} / \mathrm{RhB}\right)_{4}$ film (a) and (PSS/ $\mathrm{RhB})_{4}$ film (b) on the silicon wafer in the tapping mode, FTIR spectra of $\left(\mathrm{SnR}-\mathrm{M}-\mathrm{P}_{2} \mathrm{~W}_{15} / \mathrm{RhB}\right)_{4}(\mathrm{M}=\mathrm{Mn}, \mathrm{Co}, \mathrm{Cu}, \mathrm{Zn})$ and $(\mathrm{PSS} / \mathrm{RhB})_{4}$ films on $\mathrm{CaF}_{2}$ substrate (c), XPS spectra of $\left(\mathrm{SnR}-\mathrm{Co}-\mathrm{P}_{2} \mathrm{~W}_{15} / \mathrm{RhB}\right)_{7}$ film on $\mathrm{Si}$ substrate: $W 4 f(d), S n 3 d(e)$ and $O$ 1s (f).

$\mathrm{P}_{2} \mathrm{~W}_{15}$ observed at 1091, 954-949, 913-907 and 788-791 $\mathrm{cm}^{-1},{ }^{25,38}$ respectively, suggesting that the structures of SnR-M$\mathrm{P}_{2} \mathrm{~W}_{15}$ retained in the films. FTIR spectra of $\left(\mathrm{SnR}-\mathrm{M}-\mathrm{P}_{2} \mathrm{~W}_{15} / \mathrm{MB}\right)_{4}$
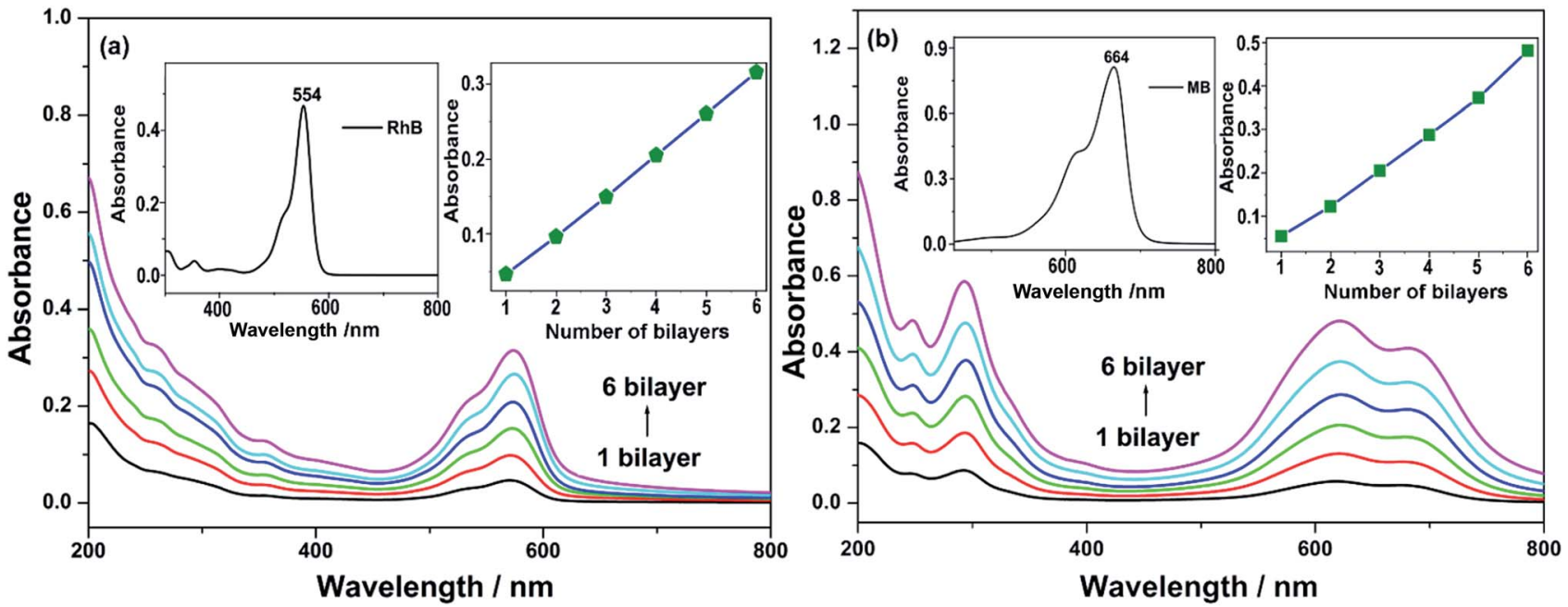

Fig. $1 \mathrm{UV} / \mathrm{Vis}$ absorption spectra of $\left(\mathrm{SnR}-\mathrm{Co}-\mathrm{P}_{2} \mathrm{~W}_{15} / \mathrm{RhB}\right)_{n}(n=1-6)$ multilayer films, and the insets of (a) show UV/Vis absorption spectrum of $\mathrm{RhB}$ aqueous solution and the absorbance of multilayer film at $\lambda_{\max }=573 \mathrm{~nm}$ as a function of $n(\mathrm{a})$; UV/Vis absorption spectra of (SnR-Co- $\mathrm{P}_{2} \mathrm{~W}_{15} /$ $\mathrm{MB})_{n}(n=1-6)$ multilayer films, and the insets of (b) show UV/Vis absorption spectrum of MB aqueous solution and the absorbance of multilayer film at $\lambda_{\max }=619 \mathrm{~nm}$ as a function of $n$ (b), respectively. 
and $(\mathrm{PSS} / \mathrm{MB})_{4}$ films were measured and shown in Fig. S18, $\uparrow$ from which we can see that the peaks at 1096, 949-946, 901-892 and $765-761 \mathrm{~cm}^{-1}$ in $\left(\mathrm{SnR}-\mathrm{M}-\mathrm{P}_{2} \mathrm{~W}_{15} / \mathrm{MB}\right)_{4}(\mathrm{M}=\mathrm{Mn}, \mathrm{Co}, \mathrm{Cu}$ and $\mathrm{Zn}$ ) films can be attributed to the characteristic vibrations of the POM skeleton. The results indicate that the structures of SnR$\mathrm{M}-\mathrm{P}_{2} \mathrm{~W}_{15}$ retained in the films. XPS measurement was used to determine the existence of POMs and their oxidation states in the multilayer film. From Fig. 2(d)-(f), the binding energies of W 4f of SnR-Cu- $\mathrm{P}_{2} \mathrm{~W}_{15}$ were located at $36.9 \mathrm{eV}$ and $34.8 \mathrm{eV}$, respectively, which are assigned to the $\mathrm{W}^{\mathrm{VI}}$ oxidation state. ${ }^{44}$ The two peaks at 494.5 and $486.1 \mathrm{eV}$ were consistent with the XPS spectrum of $\mathrm{Sn} 3 \mathrm{~d} . .^{\mathbf{4 5}, 46}$ The above results suggested that SnR-Co- $\mathrm{P}_{2} \mathrm{~W}_{15}$ in the film exists in its oxidized form. The binding energy located at 530.3 and $531.9 \mathrm{eV}$ in Fig. 2(f) were attributed to $\mathrm{O} 1 \mathrm{~s}$, in which the peak at $530.3 \mathrm{eV}$ could be ascribed to the $\mathrm{O}^{2-}$ in the framework of POMs, whereas the peak at $531.9 \mathrm{eV}$ was assigned to $\mathrm{O}^{2-}$ in carbon-oxygen bond. ${ }^{47,48}$ Fig. 3 compares the optical absorption characteristics of different series of LBL assembly films. From Fig. 3(a) we can see that $\left(\mathrm{SnR}-\mathrm{Co}-\mathrm{P}_{2} \mathrm{~W}_{15} / \mathrm{RhB}\right)_{4}$ film exhibits the strongest UV/Vis absorption intensity among its parent POMs and PSS-based films, which was ascribed to the superior adsorption ability of SnR-Co- $\mathrm{P}_{2} \mathrm{~W}_{15}$.

Meantime, it is worth noting that (PEI/SnR-Co- $\left.\mathrm{P}_{2} \mathrm{~W}_{15}\right)_{4}$ shows almost no absorbance in the visible region, which was resulted from the weak visible activity and low content of SnR-Co- $\mathrm{P}_{2} \mathrm{~W}_{15}$. To further understand the influence of structures of carboxyethyltin and POMs on the adsorption ability, Fig. 3(b) was obtained, which illustrates the following results: (1) Dawson-type open-chain carboxyethyltin-POM derivative SnR-Zn- $\mathrm{P}_{2} \mathrm{~W}_{15}$ displays significantly enhanced adsorption ability than that of Keggin-type analogue SnR-Zn-PW $\mathrm{PW}_{9}$ owing to the more negative charges of Dawson POM anions; (2) SnR-Zn-PW 9 with the openchain carboxyethyltin shows larger adsorbing capacity than that of SnR-PW 9 with the closed-ring carboxyethyltin structure, indicating that the open-chain structure benefits for the adsorption; (3) SnR-COOH itself shows certain adsorption towards RhB in despite of their identical charge types in aqueous solution, which implies that the non-electrostatic force can form between the open-chain carboxyethyltin and RhB. Fig. 3(c) reflects the
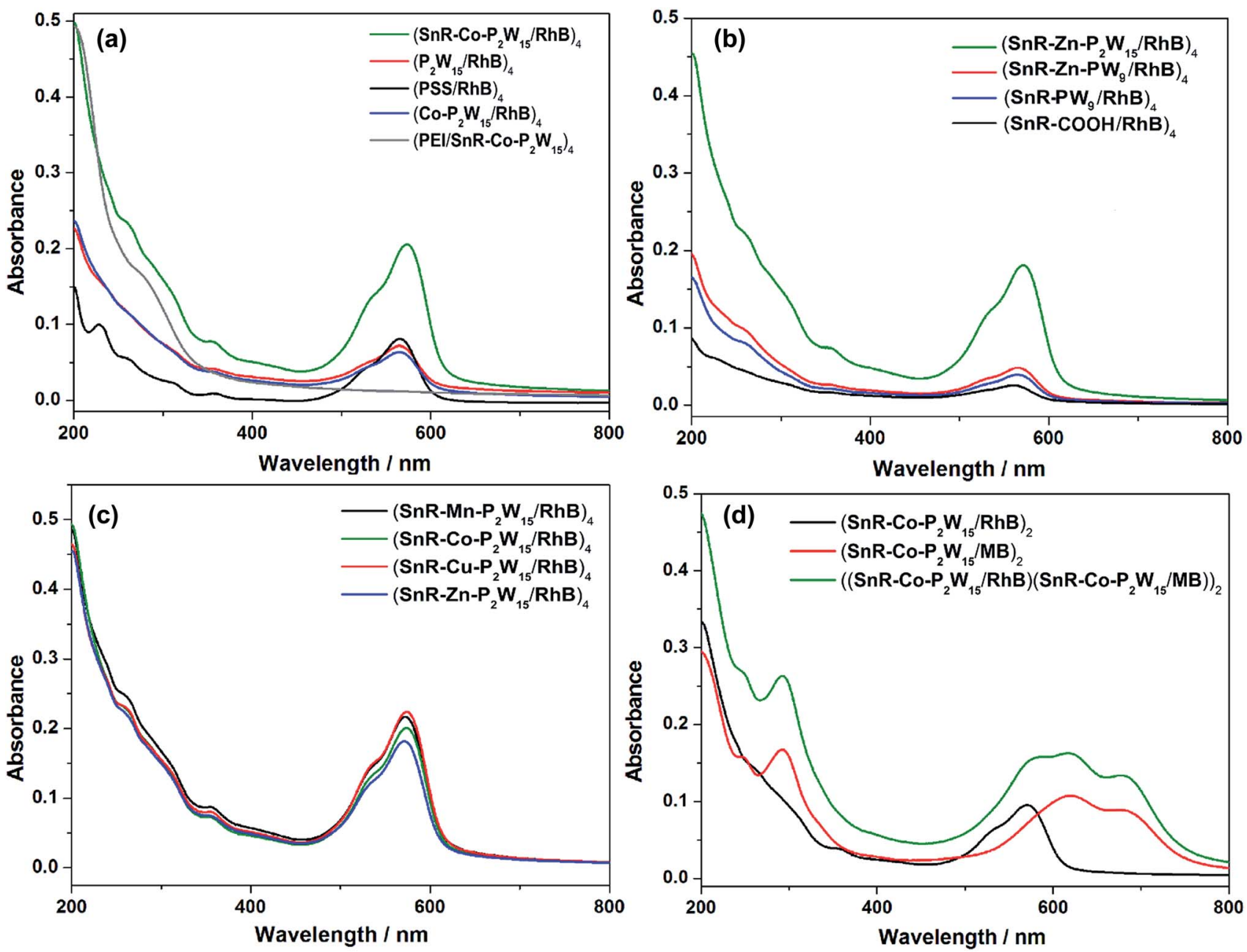

Fig. 3 UV/Vis absorption spectra of $\left(\mathrm{SnR}-\mathrm{Co}-\mathrm{P}_{2} \mathrm{~W}_{15} / \mathrm{RhB}\right)_{4}$, $\left(\mathrm{Co}-\mathrm{P}_{2} \mathrm{~W}_{15} / \mathrm{RhB}\right)_{4},\left(\mathrm{P}_{2} \mathrm{~W}_{15} / \mathrm{RhB}\right)_{4},(\mathrm{PSS} / \mathrm{RhB})_{4}$ and $\left(\mathrm{PEI} / \mathrm{SnR}-\mathrm{Co}-\mathrm{P}_{2} \mathrm{~W}_{15}\right)_{4}$ films $(a) ;(\mathrm{SnR}-$ $\left.\mathrm{PW}_{9} / \mathrm{RhB}\right)_{4},(\mathrm{SnR}-\mathrm{COOH} / \mathrm{RhB})_{4},(\mathrm{SnR}-\mathrm{Zn}-\mathrm{PW} / \mathrm{RhB})_{4}$ and $\left(\mathrm{SnR}-\mathrm{Zn}-\mathrm{P}_{2} \mathrm{~W}_{15} / \mathrm{RhB}\right)_{4}$ films (b); $\left(\mathrm{SnR}-\mathrm{M}-\mathrm{P}_{2} \mathrm{~W}_{15} / \mathrm{RhB}\right)_{4}(\mathrm{M}=\mathrm{Mn}, \mathrm{Co}, \mathrm{Cu}$ and $\mathrm{Zn})$ films (c); $\left(\mathrm{SnR}-\mathrm{Co}-\mathrm{P}_{2} \mathrm{~W}_{15} / \mathrm{RhB}\right)_{2},\left(\mathrm{SnR}-\mathrm{Co}-\mathrm{P}_{2} \mathrm{~W}_{15} / \mathrm{MB}\right)_{2}$ and $\left(\left(\mathrm{SnR}-\mathrm{Co}_{2} \mathrm{P}_{2} \mathrm{~W}_{15} / \mathrm{RhB}\right)\left(\mathrm{SnR}-\mathrm{Co}-\mathrm{P}_{2} \mathrm{~W}_{15} / \mathrm{MB}\right)\right)_{2}$ films (d), respectively. 


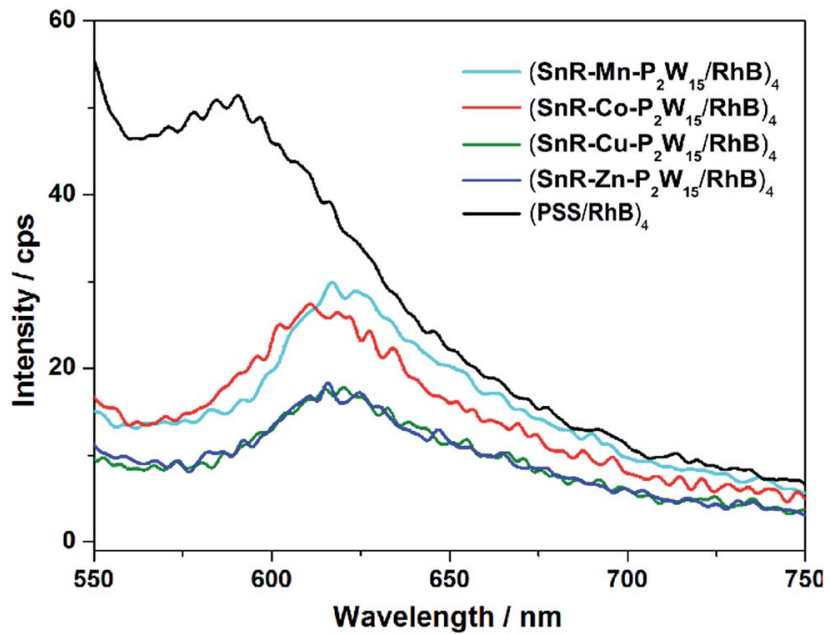

Fig. 4 Fluorescence spectra of (PSS/RhB $)_{4}$ and $\left(\mathrm{SnR}-\mathrm{M}-\mathrm{P}_{2} \mathrm{~W}_{15} / \mathrm{RhB}\right)_{4}$ $(\mathrm{M}=\mathrm{Mn}, \mathrm{Co}, \mathrm{Cu}, \mathrm{Zn})$ multilayer films $\left(\lambda_{\mathrm{ex}}=515 \mathrm{~nm}\right)$ on the quartz substrate at room temperature. absorbance differences of (SnR-M-PW $\left.{ }_{15} / \mathrm{RhB}\right)_{4}(\mathrm{M}=\mathrm{Mn}, \mathrm{Co}, \mathrm{Cu}$ and $\mathrm{Zn}$ ) films are not obvious. Furthermore, Fig. 3(d) reveals the optical responsive behaviors of LBL films can be broadened to visible and near-IR regions by incorporating $\mathrm{RhB}$ and $\mathrm{MB}$ simultaneously into the films.

The fluorescence characteristics of (PSS/RhB) $)_{4}$ and (SnR-M$\left.\mathrm{P}_{2} \mathrm{~W}_{15} / \mathrm{RhB}\right)_{4}(\mathrm{M}=\mathrm{Mn}, \mathrm{Co}, \mathrm{Cu}$ and $\mathrm{Zn})$ films have been investigated at room temperature. As shown in Fig. 4, the fluorescence spectra of LBL composite film infers that RhB can stably exist in the multilayer films. Additionally, compared with (PSS/ $\mathrm{RhB})_{4}$ film, the emission peak (SnR-M-P $\left.\mathrm{W}_{15} / \mathrm{RhB}\right)_{4}(\mathrm{M}=\mathrm{Mn}$, $\mathrm{Co}, \mathrm{Cu}$ and $\mathrm{Zn}$ ) films red shifted due to the aggregation of RhB. Meanwhile, a part of fluorescence of RhB was quenched after compositing with SnR-M- $\mathrm{P}_{2} \mathrm{~W}_{15}$, indicating that charge transfer exists between SnR-M-P $\mathrm{P}_{2}$ and RhB.

\section{Photoelectrochemical properties}

To investigate the visible photoelectric performance of the LBL films, the photocurrent response experiments were carried out by using a three-electrode system under irradiation $(\lambda>$ $420 \mathrm{~nm})$. Fig. S19 and S20† show the photocurrent responses
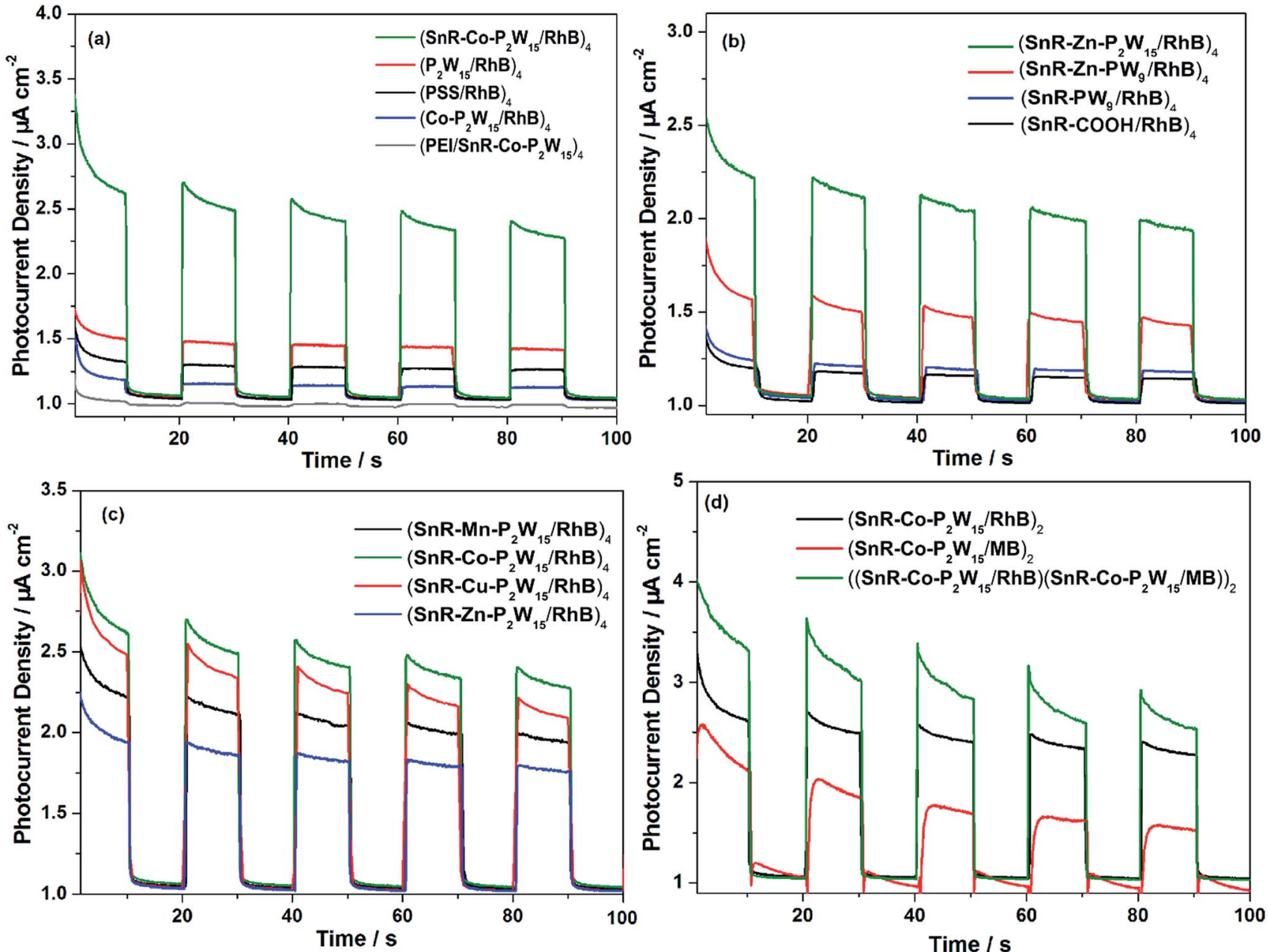

Fig. 5 Photocurrent responses of various series of LBL multilayer films under visible light irradiation $(\lambda>420 \mathrm{~nm})$ in $0.1 \mathrm{~mol} \mathrm{~L}^{-1} \mathrm{Na}_{2} \mathrm{SO}_{4}$ aqueous solution with the applied bias voltage of $0.5 \mathrm{~V} v$ s. $\mathrm{Ag} / \mathrm{AgCl}$. 
observed for films at various $\mathrm{pH}$ values and with different numbers of bilayers $(n=1-6)$, respectively. From Fig. S19† it was concluded that the photocurrent reaches to a plateau when the number of bilayers increase to 4 , which was possibly caused by the slower electron transfer rate in the thicker films.

Fig. 5(a) shows the photocurrent responses of (SnR-Co$\left.\mathrm{P}_{2} \mathrm{~W}_{15} / \mathrm{RhB}\right)_{4}$ and the control films, from which we can see that all samples displayed a fast anodic photocurrent response when the illumination is switched on. Meanwhile, notably (SnR-Co$\left.\mathrm{P}_{2} \mathrm{~W}_{15} / \mathrm{RhB}\right)_{4}$ film performs the highest photocurrent, whereas the RhB-free film (PEI/SnR-Co- $\left.\mathrm{P}_{2} \mathrm{~W}_{15}\right)_{4}$ exhibits very little photocurrent due to its low visible light activity and low carrier separation efficiency. As a result, the visible photoelectric activity of SnR-Co- $\mathrm{P}_{2} \mathrm{~W}_{15}$ can be improved by the adsorption of RhB. Furthermore, (SnR-Co- $\left.\mathrm{P}_{2} \mathrm{~W}_{15} / \mathrm{RhB}\right)_{4}$ electrode displays higher photocurrent than the photocurrent observed for (PSS/ $\mathrm{RhB})_{4},\left(\mathrm{P}_{2} \mathrm{~W}_{15} / \mathrm{RhB}\right)_{4}$ and $\left(\mathrm{Co}-\mathrm{P}_{2} \mathrm{~W}_{15} / \mathrm{RhB}\right)_{4}$ electrodes, which may be ascribed to the larger adsorbing capacity of SnR-Co$\mathrm{P}_{2} \mathrm{~W}_{15}$ towards $\mathrm{RhB}$ and more efficient visible light harvesting. To further understand this phenomenon, the photocurrent responses for SnR-M- $\mathrm{P}_{2} \mathrm{~W}_{15}(\mathrm{M}=\mathrm{Mn}, \mathrm{Cu}$ and $\mathrm{Zn})$ electrodes and their corresponding control electrodes were measured in Fig. S21, $\dagger$ which shows that SnR-M-P $\mathrm{W}_{15}(\mathrm{M}=\mathrm{Mn}, \mathrm{Cu}$ and $\mathrm{Zn})-$ based films produced the highest photocurrent responses as compared to their parent POMs and PSS-based films. Besides, Fig. 5(b) compared the photocurrent responses of POMs with different carboxyethyltin structure and POM structure. In accordance with the UV/Vis spectral responses in Fig. 3(b), SnR$\mathrm{Zn}-\mathrm{P}_{2} \mathrm{~W}_{15}$ based film displays the highest photocurrent response as compared to $\mathrm{SnR}_{-} \mathrm{PW}_{9}, \mathrm{SnR}-\mathrm{Zn}-\mathrm{PW}_{9}$ and SnR$\mathrm{COOH}$. Meantime, there is a slight difference between the photocurrents generated from four isostructural double armed sandwich-type carboxyethyltin-decorated POMs. From Fig. 5(c) it was observed that SnR-Co- $\mathrm{P}_{2} \mathrm{~W}_{15}$-based photoelectrode presents the optimal photoelectric performance than other SnR-M$\mathrm{P}_{2} \mathrm{~W}_{15}$-based ( $\mathrm{M}=\mathrm{Mn}, \mathrm{Cu}$ and $\mathrm{Zn}$ ) electrodes. In addition, the other organic dye MB was applied to composite with SnR-Co$\mathrm{P}_{2} \mathrm{~W}_{15}$. Accordingly, the photocurrent response of (SnR-Co$\left.\mathrm{P}_{2} \mathrm{~W}_{15} / \mathrm{MB}\right)_{4}$ film was examined and shown in Fig. S22, $\dagger$ which also proved (SnR-Co- $\left.\mathrm{P}_{2} \mathrm{~W}_{15} / \mathrm{MB}\right)_{4}$ film exhibited better photoelectric properties than the reference films including $\left(\mathrm{P}_{2} \mathrm{~W}_{15}\right)$ $\mathrm{MB})_{4},\left(\mathrm{Co}-\mathrm{P}_{2} \mathrm{~W}_{15} / \mathrm{MB}\right)_{4}$ and (PSS/MB $)_{4}$ films. In order to further broaden the absorption spectra of POMs, RhB and MB were simultaneously assembled into SnR-Co- $\mathrm{P}_{2} \mathrm{~W}_{15}$-based LBL films, and its photocurrent response was superior to the photocurrents of (SnR-Co- $\left.\mathrm{P}_{2} \mathrm{~W}_{15} / \mathrm{MB}\right)_{4}$ and (SnR-Co- $\left.\mathrm{P}_{2} \mathrm{~W}_{15} / \mathrm{RhB}\right)_{4}$ films in Fig. 5(d). Furthermore, some organic dye-POM LBL films have been reported, such as hemicyanine-POM films. They show obvious cathodic photocurrent response, which was generated based on charge transfer excitation of hemicyanine in the film. ${ }^{49-51}$ Meantime, SnR-M-P $\mathrm{P}_{15}$-based $(\mathrm{M}=\mathrm{Mn}, \mathrm{Co}, \mathrm{Cu}$ and $\mathrm{Zn)}$ electrodes exhibit anodic photocurrent, which indicates that different types of photocurrent can be produced by assembling suitable POMs and organic dyes. In addition, the stability of the films was studied as shown in Fig. S23 and S24. $\dagger$ The absorbance of (SnR-Co- $\left.\mathrm{P}_{2} \mathrm{~W}_{15} / \mathrm{RhB}\right)_{4}$ and $\left(\mathrm{SnR}-\mathrm{Co}-\mathrm{P}_{2} \mathrm{~W}_{15}\right)$ $\mathrm{MB})_{4}$ films reduced by $30.5 \%$ and $3.02 \%$, respectively, after dipping in aqueous solution for $2 \mathrm{~h}$, which concluded that (SnRCo- $\left.\mathrm{P}_{2} \mathrm{~W}_{15} / \mathrm{MB}\right)_{4}$ film is more stable than RhB-based film.

\section{Conclusions}

In summary, we present data demonstrating the photoelectric performance of the LBL multilayer photoelectrode (SnR-M$\mathrm{P}_{2} \mathrm{~W}_{15} /$ dye $)_{n}$ (dye $=\mathrm{RhB}$ or $\left.\mathrm{MB}, n=1-6\right)$ was obviously enhanced owing to their efficient light harvesting in visible region and strong adsorption capacity of SnR-M- $\mathrm{P}_{2} \mathrm{~W}_{15}$. And the results demonstrate that Dawson structure and functionalization of open-chain carboxyethyltin play significant roles on the superior photoelectric properties. Furthermore, the transitional metal incorporated in SnR-M- $\mathrm{P}_{2} \mathrm{~W}_{15}$ also matters and SnR-Co$\mathrm{P}_{2} \mathrm{~W}_{15}$ was proved to lead to the optimal effect. Meanwhile, the optical absorption characteristics of SnR-M-P $\mathrm{W}_{15}$ can be further expanded to visible and near-IR regions through simultaneously incorporating both $\mathrm{RhB}$ and $\mathrm{MB}$ in SnR-M$\mathrm{P}_{2} \mathrm{~W}_{15}$-based electrodes, which induces the ascending photoelectric performances. Our work opens up possibilities on the recycle of dye in wastewater for further use on solar energy conversion. Further work on compositing Dawson-type openchain carboxyethyltin functionalized POMs with other photoactive materials are under going on.

\section{Acknowledgements}

This work was financially supported by the National Natural Science Foundation of China (No. 21671091, 21601077, 21503103 and 21573099), and Youth scientific research project of Liaoning Normal University (No. LS2014L018, LS2015L008 and LS2015L006).

\section{Notes and references}

1 X. Li, D. Q. Bi, C. Y. Yi, J. D. Décoppet, J. S. Luo, S. M. Zakeeruddin, A. Hagfeldt and M. Grätzel, Science, 2016, 353, 58.

2 B. O'Regan and M. Grätzel, Nature, 1991, 353, 737.

3 J. Liu, Y. Liu, N. Y. Liu, Y. Z. Han, X. Zhang, H. Huang, Y. Lifshitz, S. T. Lee, J. Zhong and Z. H. Kang, Science, 2015, 347, 970.

4 M. Z. Yu, W. D. McCulloch, D. R. Beauchamp, Z. J. Huang, X. D. Ren and Y. Y. Wu, J. Am. Chem. Soc., 2015, 137, 8332.

5 G. E. Zervaki, P. A. Angaridis, E. N. Koukaras, G. D. Sharma and A. G. Coutsolelos, Inorg. Chem. Front., 2014, 1, 256.

6 J. H. Kim, H. Kaneko, T. Minegishi, J. Kubota, K. Domen and J. S. Lee, ChemSusChem, 2016, 9, 61.

7 A. E. Shalan, T. Oshikiri, S. Narra, M. M. Elshanawany, K. Ueno, H. P. Wu, K. Nakamura, X. Shi, E. W. G. Diau and H. Misawa, ACS Appl. Mater. Interfaces, 2016, 8, 33592.

8 J. K. Gao, J. W. Miao, P. Z. Li, W. Y. Teng, L. Yang, Y. L. Zhao, B. Liu and Q. C. Zhang, Chem. Commun., 2014, 50, 3786.

9 M. Alaaeddine, Q. Zhu, D. Fichou, G. Izzet, J. E. Rault, N. Barrett, A. Proust and L. Tortech, Inorg. Chem. Front, 2014, 1, 682 . 
10 J. M. Liu, X. L. Chen, J. Fang, Y. Zhao and X. D. Zhang, Sol. Energy Mater. Sol. Cells, 2015, 138, 41.

11 H. Lee, J. Lee, Y. H. Lee, J. Lee and M. Yoon, J. Mater. Chem., 2011, 21, 12829.

12 W. Yang, L. H. Gao and K. Z. Wang, Polyhedron, 2014, 82, 80.

13 X. Z. Luo, F. Y. Li, B. B. Xu, Z. X. Sun and L. Xu, J. Mater. Chem., 2012, 22, 15050.

14 Y. X. Jiang, Y. L. Yang, L. S. Qiang, R. Q. Fan, H. P. Ning, L. Li, T. L. Ye, B. Yang and W. W. Cao, J. Power Sources, 2015, 278, 527.

15 J. K. Gao, J. W. Miao, Y. X. Li, R. Ganguly, Y. Zhao, O. Lev, B. Liu and Q. C. Zhang, Dalton Trans., 2015, 44, 14354.

16 L. Chen, W. L. Chen, H. Q. Tan, J. S. Li, X. J. Sang and E. B. Wang, J. Mater. Chem. A, 2016, 4, 4125.

17 D. Xu, W. L. Chen, J. S. Li, X. J. Sang, Y. Lu, Z. M. Su and E. B. Wang, J. Mater. Chem. A, 2015, 3, 10174.

18 X. W. Guo, J. S. Li, X. J. Sang, W. L. Chen, Z. M. Su and E. B. Wang, Chem.-Eur. J., 2016, 22, 3234.

19 L. F. He, L. Chen, Y. Zhao, W. L. Chen, C. H. Shan, Z. M. Su and E. B. Wang, J. Power Sources, 2016, 328, 1.

20 J. S. Li, X. J. Sang, W. L. Chen, L. C. Zhang, Z. M. Zhu, Y. G. Li, Z. M. Su and E. B. Wang, J. Mater. Chem. A, 2015, 3, 14573.

21 J. J. Walsh, C. T. Mallon, A. M. Bond, T. E. Keyes and R. J. Forster, Chem. Commun., 2012, 48, 3593.

22 I. Ahmed, R. Farha, M. Goldmann and L. Ruhlmann, Chem. Commun., 2013, 49, 496.

23 C. Boglio, K. Micoine, É. Derat, R. Thouvenot, B. Hasenknopf, S. Thorimbert, E. Lacôte and M. Malacria, J. Am. Chem. Soc., 2008, 130, 4553.

24 X. J. Sang, J. S. Li, L. C. Zhang, Z. J. Wang, W. L. Chen, Z. M. Zhu, Z. M. Su and E. B. Wang, ACS Appl. Mater. Interfaces, 2014, 6, 7876.

25 H. Sun, L. Y. Guo, J. S. Li, J. P. Bai, F. Su, L. C. Zhang, X. J. Sang, W. S. You and Z. M. Zhu, ChemSusChem, 2016, 9, 1125.

26 X. J. Sang, J. S. Li, L. C. Zhang, Z. M. Zhu, W. L. Chen, Y. G. Li, Z. M. Su and E. B. Wang, Chem. Commun., 2014, 50, 14678.

27 X. H. Wang, J. J. Ding, S. W. Yao, X. X. Wu, Q. Q. Feng, Z. H. Wang and B. Y. Geng, J. Mater. Chem. A, 2014, 2, 15958. 28 A. X. Yan, S. Yao, Y. G. Li, Z. M. Zhang, Y. Lu, W. L. Chen and E. B. Wang, Chem.-Eur. J., 2014, 20, 6927.

29 Y. F. Song and R. Tsunashima, Chem. Soc. Rev., 2012, 41, 7384. 30 A. Rani, K. Chung, J. Kwon, S. J. Kim, Y. H. Jang, Y. J. Jang, L. N. Quan, M. Yoon, J. H. Park and D. H. Kim, ACS Appl. Mater. Interfaces, 2016, 8, 11488.
31 W. M. Gao, T. Yu, L. X. Wu and L. H. Bi, Chem. Commun., 2016, 52, 10403.

32 B. Qin, H. Y. Chen, H. Liang, L. Fu, X. F. Liu, X. H. Qiu, S. Q. Liu, R. Song and Z. Y. Tang, J. Am. Chem. Soc., 2010, 132, 2886.

33 R. G. Finke, M. W. Droege and P. J. Domaille, Inorg. Chem., 1987, 26, 3886.

34 C. J. Cómez-García, J. J. Borrás-Almenar, E. Coronado and L. Ouahab, Inorg. Chem., 1994, 33, 4016.

35 C. J. Gómez-García, E. Coronado and J. J. Borrás-Almenar, Inorg. Chem., 1992, 31, 1667.

36 R. G. Finke and T. J. R. Weakley, J. Chem. Crystallogr., 1994, 24, 123.

37 R. E. Hutton and J. W. Burley, J. Organomet. Chem., 1978, 156, 369.

38 J. P. Bai, F. Su, H. T. Zhu, H. Sun, L. C. Zhang, M. Y. Liu, W. S. You and Z. M. Zhu, Dalton Trans., 2015, 44, 6423.

39 B. Zhang, L. C. Zhang, Y. J. Zhang, F. Su, W. S. You and Z. M. Zhu, RSC Adv., 2015, 5, 47319.

40 H. Yang, L. C. Zhang, L. Yang, X. L. Zhang, W. S. You and Z. M. Zhu, Inorg. Chem. Commun., 2013, 29, 33.

41 F. X. Xiao, J. W. Miao and B. Liu, J. Am. Chem. Soc., 2014, 136, 1559.

42 N. Bhandary, A. P. Singh, S. Kumar, P. P. Ingole, G. S. Thakur, A. K. Ganguli and S. Basu, ChemSusChem, 2016, 9, 2816.

43 S. Y. Gao, R. Cao and C. P. Yang, J. Colloid Interface Sci., 2008, 324, 156.

44 L. Xu, H. Y. Zhang, E. B. Wang, D. G. Kurth and Z. Li, J. Mater. Chem., 2002, 12, 654.

45 H. Willemen, L. F. Wuyts, D. F. Van De Vondel and G. P. Van Der Kelen, J. Electron Spectrosc. Relat. Phenom., 1977, 11, 245.

46 R. Shiratsuchi, K. Hongo and G. Nogami, J. Electrochem. Soc., 1992, 139, 2544.

47 D. L. Hoof, D. G. Tisley and R. A. Walton, J. Chem. Soc., Dalton Trans., 1973, 2, 200.

48 R. J. Colton and J. W. Rabalais, Inorg. Chem., 1976, 15, 236.

49 L. H. Gao, Q. L. Sun, J. M. Qi, X. Y. Lin and K. Z. Wang, Electrochim. Acta, 2013, 92, 236.

50 H. L. Zhang, Y. B. Wang, L. H. Gao and K. Z. Wang, J. Appl. Electrochem., 2016, 46, 505.

51 L. H. Gao, J. F. Zhang, H. L. Wang, X. Y. Lin, J. M. Qi and K. Z. Wang, Electrochim. Acta, 2015, 166, 215. 